\title{
ANÁLISE DE NECESSIDADES EM INGLÊS: PROPOSIÇÃO E REFLEXÕES SOBRE UM INSTRUMENTO DE COLETA DE INFORMAÇÕES
}

\section{Needs analysis in English: the proposal and reflections upon an instrument to collect information.}

\begin{abstract}
RESUMO: Este artigo envolve a análise de necessidades prevista no ensino de inglês para fins especificos (ISP), baseado na centralização do ensinar e do aprender no aluno, e considerando o seu conhecimento necessário, desejos e anseios. Descreve-se e discutese um instrumento de coleta de informações já utilizado em duas turmas da disciplina Oficina de Leitura e Escrita em Língua Estrangeira IV (Inglês) do curso de Bacharelado em Letras de um centro federal de educação em Minas Gerais. Defende-se que esta proposta pode ser útil para outros contextos, adaptada a situações diversas de ensino de línguas para fins específicos e contribui para o reforço do papel central a ser ocupado pelo aprendiz no ensino e na aprendizagem de línguas na medida em que a ele é dada a voz sobre suas necessidades.
\end{abstract}

PALAVRAS-CHAVE: Inglês para fins específicos; Análise de necessidades; Instrumento.

\begin{abstract}
This article involves needs analysis foreseen in the teaching of English for specific purposes (ESP), based on the learner centredness in teaching and learning, and considering his necessary knowledge, wants and anxieties. An instrument to collect information is described and discussed, which has already been used twice in the subject Reading and Writing in Foreign Language IV (English) in a Bachelor Course in Language and Literature at a federal educational center in Minas Gerais. It is defended that the proposal can be useful in other contexts, adapted to diverse ESP situations and contributes to reinforce the learner's central role in language teaching and learning as his voice about necessities is considered.
\end{abstract}

KEYWORDS: English for Specific Purposes; Needs Analysis; Instrument. 


\section{Introdução}

O ensino de línguas para fins específicos, seja visando a atuação profissional do aprendiz seja voltado para a sua inserção no meio acadêmico, é proposto com base em análise de necessidades de quem vai aprender ou está aprendendo determinado idioma. Isso requer a centralização do ensinar e do aprender na figura do aluno, a começar pela consideração daquilo que se institui na sociedade como necessário a este aprendiz em termos de conhecimento daquela língua, e o que ele deseja saber e fazer na e com a línguaalvo. Para Hutchinson; Waters (1987), o que distingue a abordagem de ensino de inglês para fins específicos do chamado ensino de inglês geral (General English) é justamente a proposição de uma consciência das necessidades por parte de professores e aprendizes.

A análise de necessidades pode ser feita de várias maneiras, formalmente ou informalmente, assumindo diversas intenções: planejamento e delineamento do curso, determinação de conteúdos e gêneros textuais a serem trabalhados, ativação de ou acesso ao conhecimento prévio dos alunos em diversos aspectos (estratégias, linguístico, discursivo, contexto). Este pode ser encarado como um momento de pesquisa pedagógica (LANKSHEAR; KNOBEL, 2008), entendida aqui como uma prática de caráter sistematizado em que há um ou mais questionamentos a serem respondidos com o intuito de colaborar para o entendimento do contexto, ou para a proposta de uma intervenção ou metodologia de ensino, como em alguns casos. Para tal, e como em toda pesquisa, é necessário um planejamento adequado, uma fundamentação pertinente, uma maneira de coletar informações e de analisá-las. Essa pesquisa pode ter caráter quantitativo ou qualitativo ou ambos, como mostrado nas sínteses de algumas neste artigo, dependendo da natureza e do propósito pretendido da análise de necessidades.

Várias maneiras de se coletar informações numa análise de necessidades no curso de línguas estrangeiras para fins específicos têm sido relatados: questionário aberto a alunos dos cursos (ALMEIDA; SILVA, 2016), questionários com questões abertas e fechadas sobre gêneros usados na vida acadêmica (RAMOS; LIMA-LOPES; GAZOTTIVALLIM, 2004), questionários direcionados a trabalhadores da área já em serviço (SILVA; BONIFÁCIO, 2015), observação e consulta informal (SAES, 2013). Pode haver a conjugação de vários instrumentos dependo do foco da pesquisa, como acontece na 
pesquisa de Sarmento (2012), em que a autora pretendeu identificar as necessidades de aprendizagem em inglês de alunos de Turismo, envolvendo seus desejos e carências, as necessidades dos professores e do coordenador do curso com relação à língua, e as necessidades impostas pela situação-alvo dos profissionais (egressos) em empresas. Assim, a autora se valeu de questionários, entrevistas e análise de documentos do curso, e concluiu que a análise de necessidades é importante para redesenhar a proposta, atendendo mais de perto às demandas dos sujeitos ali envolvidos.

A proposta deste artigo é apresentar um instrumento de coleta de informações elaborado e utilizado pelo autor em duas turmas da disciplina Oficina de Leitura e Escrita em Língua Estrangeira IV (Inglês) do curso de Bacharelado em Letras do Centro Federal de Educação Tecnológica de Minas Gerais (CEFET-MG). Defende-se que esta proposta pode ser útil para outros contextos, adaptada a situações diversas de ensino de línguas para fins específicos e contribui para o reforço do papel central a ser ocupado pelo aprendiz no ensino e na aprendizagem de línguas, sendo ele, e não a proposição ou delineamento do curso, o foco desta análise de necessidades.

Isso não significa desconsiderar a importância das análises de necessidades enfocando os objetivos e delineamentos de cursos de línguas para fins específicos. Ao contrário, reconhecendo a necessidade de tais iniciativas, o que se argumenta é que a análise de necessidades não deve servir apenas a esses propósitos, mas também para dar voz ao aluno sobre os diversos aspectos relacionados à atividade de aprender inglês de maneira mais livre. A cada turma nova certamente o docente precisa conhecer seus alunos, suas experiências, anseios, desejos, necessidades em termos de conhecimento para o andamento das aulas, observado o contexto de ensino e de aprendizagem em que ele e os alunos se inserem.

Este artigo é organizado da seguinte maneira. Primeiramente, apresentam-se aspectos teóricos relativos à análise de necessidades no ensino de línguas para fins específicos. Em segundo lugar, é descrito o contexto em que aconteceu a elaboração do instrumento descrito. Em seguida, este é apresentado e comentado, propondo-se adaptações para situações diferentes e evidenciam-se as informações que têm sido conseguidas nas experiências em que o instrumento foi utilizado. Nas considerações finais, retoma-se a proposta do artigo para se apresentar as reflexões do autor. 


\section{A análise de necessidades no ensino de línguas para fins específicos}

A ênfase em necessidades específicas do aluno ou de um grupo de alunos é o que diferencia o ensino de inglês para fins específicos (ESP) ${ }^{1}$ do ensino de inglês para fins gerais (General English), determinando prioridade de habilidades e conhecimentos linguísticos considerados mais importantes para os alunos atingirem seus objetivos com a língua. Enquanto o ensino do inglês geral ocorre em contextos em que o inglês é língua materna, ou segunda língua ou língua estrangeira, é neste último contexto em que mais se insere o ensino de inglês para fins específicos. Assim, o ESP caracteriza-se como uma abordagem de ensino de línguas em que os aprendizes são o foco (learner's centre approach, como explicam Hutchinson; Waters, 1987). De maneira geral, como mostram estes autores, o ensino de ESP pode ter como finalidade preparar o aluno para atuar em contexto profissional (EOP, ou English for Occupational Purposes) ou para atuar em contexto acadêmico (EAP, ou English for Academic Purposes). Em ambos os casos, o foco pode ser nas habilidades orais ou escritas, ou ainda em todas elas, dependendo da área de atuação em que se inserem os aprendizes (Economia, Linguística, Literatura, Saúde, Educação, Ciências Sociais, Engenharias, dentre outras).

Jordan (1998), por exemplo, mostra a necessidade de determinados aprendizes de EAP saberem, em contexto de imersão, não apenas lidar com os textos escritos (leitura e escrita) no meio acadêmico, mas também desenvolver habilidades para realizarem atividades tais como tomar notas em palestras (habilidades de compreensão oral e escrita) e participarem de eventos apresentando trabalhos (produção oral e escrita).

Como esclarece Vilaça (2010), a aprendizagem do inglês, nesta abordagem, deve acontecer de maneira atrelada ao que se pretende fazer com a língua preparando-se para a utilização do idioma na realização de fazeres específicos necessários. Esse mesmo autor explica que a identificação dessas necessidades pode se dar tendo em vista "habilidades linguísticas, competências, funções comunicativas, tópicos lexicais, entre outros fatores" (VILAÇA, 2010, p. 8).

\footnotetext{
${ }^{1}$ ESP é a sigla do termo em inglês English for Specific Purposes.
} 
Segundo Hutchinson e Waters (1987), o ganho maior dessa abordagem pode ser não apenas saber que necessidades específicas o aprendiz tem, mas talvez a consciência que se adquire de e sobre tais necessidades. Para estes autores, as necessidades dos alunos devem ser pensadas em termos de necessidades - alvo (target needs) e necessidades de aprendizagem (learning needs). As primeiras são referentes ao uso da língua (o que saber em que contexto), considerando o que os alunos precisam, querem e sentem falta com relação ao conhecimento e uso da língua. Já as necessidades de aprendizagem envolvem a situação em si, como os aprendizes aprendem, os recursos disponíveis e necessários, quem são esses aprendizes, e ainda o papel do ensino e da aprendizagem de inglês para fins específicos para este público. Nesta perspectiva, também com base nesses autores, é preciso estar atento àquilo que os alunos demonstram precisar em termos de conhecimentos linguísticos, discursivos, de estratégias e habilidades, o que eles gostariam de saber, e ainda do que eles sentem falta no seu conhecimento da e sobre a língua.

Hutchinson e Waters (1987, p.62-63) sugerem questionamentos que podem ajudar na elaboração de um curso de inglês para fins específicos. Souza (2014, p. 8) elenca essas questões como exposto no quadro 1:

Quadro 1: Questionamentos na elaboração de curso de inglês para fins específicos

\begin{tabular}{|c|c|}
\hline $\begin{array}{l}\text { Estrutura para elaboração de análise da } \\
\text { Situação-Alvo }\end{array}$ & $\begin{array}{l}\text { Estrutura para elaboração de análise da } \\
\text { Situação de Aprendizagem }\end{array}$ \\
\hline $\begin{array}{l}\text { - Por que a língua é necessária? } \\
\text { - Como será utilizada? } \\
\text { - Qual será a área de atuação? } \\
\text { - Com quem o aprendiz irá utilizar a } \\
\text { - língua? } \\
\text { - Onde a língua será utilizada? } \\
\text { Quando a língua será utilizada? }\end{array}$ & $\begin{array}{l}\text { - Por que o aprendiz está frequentando } \\
\text { - o curso? } \\
\text { - } \quad \text { Quais as fontes disponíveis? } \\
\text { - Quem são os aprendizes? } \\
\text { - Onde o curso será ministrado? } \\
\text { - Quanto o curso será ministrado? }\end{array}$ \\
\hline
\end{tabular}

Fonte: SOUZA (2014, p.8)

Dudley-Evans e St John (2009), de maneira similar aos autores mencionados acima, definem as seguintes áreas em que se pode definir a análise de necessidades em cursos de inglês para fins específicos: tarefas e atividades do aprendiz no futuro para as quais o inglês é necessário, habilidades e conhecimento de língua usado em situações alvo (no caso, nos meios acadêmico ou profissional, incluindo conhecimento de língua e de discurso na área), análise subjetiva considerando expectativas, desejos, razões para se 
aprender e experiências prévias, identificação das situações de uso e de conhecimento de inglês no momento do curso e informações sobre o meio onde o curso acontecerá.

Algumas necessidades podem ser impostas pelas situações sociais em que acontece a situação de ensino e aprendizagem (JORDAN, 1998), como por exemplo, participar de um curso de pós-graduação no exterior, além das necessidades específicas dos próprios aprendizes. Mas pode ser interessante desviar do excesso de textos e situações acadêmicas para ir ao encontro de algumas necessidades e anseios dos estudantes. É comum na formação acadêmica e profissional, então, que a análise de necessidade seja tomada em conta previamente na proposição do curso, visando a um público de perfil determinado, considerando o conhecimento dito como necessário para se atingir o objetivo. Nestes casos, o foco é muito mais no ensino a ser ofertado do que no aluno que precisa frequentar o curso.

Essa visão parece estar presente na experiência relatada por Saes (2013). Esta autora reflete sobre as dificuldades e reprovações de alguns alunos do curso de Tecnologia da Informação em exames de proficiência em inglês. A partir das reflexões, do que se espera do aluno nesses exames e levando em conta as necessidades requeridas pelos alunos na situação-alvo e suas necessidades de aprendizagem, a autora e professora lança mão de [...] "observação e consulta informal com outros professores das disciplinas" (SAES, 2013, p. 97) para identificar as necessidades dos alunos que precisavam se submeter aos exames do curso. Com isso, nos dizeres da autora, foi possível elaborar o curso, pois

[...] foi possível identificar a maior parte dos aspectos, tendo em vista que já conhecíamos o perfil da maioria dos alunos. Além das situações já mencionadas, foi possível inferir as dificuldades de aprendizagem dos alunos, qual metodologia poderia atender às suas expectativas; a possibilidade de participar de atividades extracurriculares ou a necessidade de oferecer apoio por meio de atividades semipresenciais. (SAES, 2013, p. 97)

Percebe-se, no relato da professora, que a análise de necessidades considera o aluno de maneira indireta, tomando como ponto de partida a observação docente e consulta realizada por ela aos professores da área específica, e a partir daí há inferência 
das dificuldades dos alunos. Neste caso, não se demonstra ter dado voz ao aluno no momento da análise de suas necessidades.

Já outra experiência de análise de necessidades relatada por Ramos, Lima-Lopes e Gazotti-Vallim (2004) leva em conta informações fornecidas pelos próprios alunos na forma de questionário com questões fechadas, em sua maioria. O objetivo neste caso era ter subsídios para reformular um curso de leitura de textos em ambiente acadêmico com ênfase em gêneros textuais. Nos dizeres dos autores, “[...] para que essa reformulação curricular pudesse ocorrer, o grupo de professores-pesquisadores desse curso decidiu fazer um levantamento de necessidades dos alunos no que diz respeito aos gêneros que esses alunos precisariam utilizar em seus contextos de estudo" (RAMOS; LIMA-LOPES; GAZOTTI-VALLIM, 2004, p. 3). A proposta relatada demonstra que o instrumento criado para coleta de informações cumpriu o papel de fornecer as informações requeridas pelos pesquisadores, mesmo sofrendo algumas modificações de um ano para outro quando aconteceu a pesquisa. Os autores apresentam uma visão crítica sobre o instrumento, mostrando a limitação do uso de questões e listas prontas no instrumento. Assim eles se expressam:

um outro aspecto a ser comentado é a lista dos gêneros fornecida no questionário para que os alunos numerassem sua frequência de leitura e grau de importância. Acreditamos que o fato de essa lista ter sido fornecida aos alunos pode ter influenciado as respostas, visto ser uma lista relativamente extensa e que traz, implícito, o nosso conhecimento sobre os gêneros abordados. Conhecimento esse, talvez, diferente do conhecimento que os alunos possuem a respeito dos gêneros com os quais têm contato em suas rotinas acadêmicas. Talvez se essas perguntas tivessem sido abertas, alguns gêneros diferentes pudessem ter emergido. Entretanto, a opção por questões fechadas foi feita para facilitar as respostas dos informantes, com o intuito de funcionar como exemplos de gêneros acadêmicos mais comumente utilizados no contexto em questão. (RAMOS; LIMA-LOPES; GAZOTTI-VALLIM, 2004, p. 21)

$\mathrm{Na}$ visão dos autores, e com a qual se alinha o presente artigo, a análise de necessidades não é para sempre, mas tem um caráter contínuo, como o instrumento de coleta de informações pode ter. Ao final, esses autores apontam a necessidade de que pesquisas paralelas possam fornecer novas informações sobre pontos específicos de um 
contexto de ensino e aprendizagem e de pesquisa. Assim vários instrumentos podem ser usados no momento da análise de necessidades.

Defende-se, neste artigo, que a análise de necessidades num curso de inglês para fins específicos pode ser construída em conjunto com os aprendizes, como fazem os autores acima mencionados, a partir de suas realidades vivenciadas anteriormente e no momento em que o curso se dá, e não baseada apenas em estudos externos ao contexto de ensino e de aprendizagem ou anteriores. Acredita-se que os alunos envolvidos num curso dessa natureza têm o direito de se expressar e de ter consciência de sua história de aprendizagem, de suas experiências com a língua inglesa, devem conhecer o contexto sócio-profissional-acadêmico do qual poderão fazer parte uma vez tendo certo domínio da língua, merecem ser conscientizados de seus conhecimentos linguísticos, discursivos, de habilidades e de estratégias, enfim, de todo o processo de aprender e do processo de ensinar em que o professor se insere como agente. Também, seguindo o que propõem Hutchinson e Waters (1987), não se pode deixar de levar em conta os desejos dos alunos, seus anseios, o que pode interferir na atitude que têm no curso e, sobretudo, do inglês em geral. Para subsidiar essa ideia, assume-se, que aprendizes são seres humanos ativos, que não necessariamente aprendem tudo o que se ensina, e nem têm conhecimento nulo da estrutura linguística da língua alvo (LONG, 2005, p. 3).

Indo mais além, lidar com os anseios dos alunos faz parte do papel de educador a ser assumido pelo professor de inglês para fins específicos. O professor não se restringe a mero ministrador de um conteúdo previsto na proposta curricular do curso a partir de uma metodologia, mas pode, como educador, assumir perante os alunos uma postura mais dialógica, no sentido defendido por Freire (2000). Entende-se, aqui, que isso envolve saber a respeito das vivências e necessidades dos alunos, suas experiências bem ou malsucedidas, suas competências prévias, seus anseios e suas possibilidades, sem assumir uma postura de opressor sobre o oprimido (FREIRE, 2000). Acredita-se que tal postura pode ajudar os alunos a se conscientizarem do processo de aprender, tanto a partir das experiências prévias como pensando sobre a experiência atual tornando o ensinar e o aprender mais abertos, sendo essa responsabilidade dividida entre docentes e discentes.

Foi com isso em mente que se construiu o instrumento de análise de necessidades aqui apresentado e explicado. Nas próximas seções, possíveis adaptações do mesmo 
também são cogitadas. Anteriormente, porém, faz-se necessário descrever o contexto em que a disciplina e o instrumento se inseriram.

\section{O contexto em que a proposta se inseriu originariamente}

O bacharelado em Letras da instituição em que foi usado o instrumento aqui apresentado tem como linha de formação específica as tecnologias da edição. Segundo o projeto de criação do próprio curso (RIBEIRO ET AL, 2010, p. 4), a sua proposta

[...] explora as possibilidades das propostas curriculares da área da Letras, buscando interfaces com outras áreas tais como a Comunicação Social, a Administração de Empresas e a Engenharia de Computação, sem perder de vista o horizonte próprio da formação em Letras.

A formação pretendida é de um profissional com conhecimentos específicos dos campos da Linguística e da Literatura, direcionado para os processos editoriais em meios impresso e digital. Essa formação profissional prevê pessoas "[...] com perfil afinado com a atual conjuntura dos estudos relativos às novas linguagens e com a demanda por profissionais capazes de lidar com diferentes mídias nos processos de intersemiose" (RIBEIRO ET AL, 2010, p. 4).

Este curso de Letras está organizado em eixos temáticos, a saber:

. Eixo 1: Estudos de Linguagem;

- Eixo 2; Estudos Literários;

- Eixo 3: Ciências Humanas e Cultura;

- Eixo 4: Línguas Estrangeiras Instrumentais;

- Eixo 5: Prática de Produção, Edição e Revisão de Textos;

- Eixo 6: Processo e Produção Editorial;

- Eixo 7: Prática Profissional e Integração Curricular.

(Fonte: RIBEIRO ET AL., 2010, p. 23)

As línguas estrangeiras são consideradas, nesta proposta de curso, numa perspectiva instrumental. No eixo 4, estão propostos e sendo executados desde a criação do curso, os seguintes conteúdos, aqui transcritos do projeto (RIBEIRO ET AL., 2010, p. 27):

Leitura de textos autênticos em língua estrangeira. Natureza, modelos, funções, processos e estratégias de leitura. Leitura como ato comunicativo e social. Aspectos interativos entre leitor/texto e 
leitor/autor. Desenvolvimento da leitura crítica dos mais variados gêneros. Estudo de aspectos morfológicos e sintáticos da língua estrangeira: análise de classes de palavras e estruturas sintáticas, sintagmas e orações. A relação entre contexto, texto, escritor e leitor. Identificação de diferentes gêneros discursivos. Coesão e coerência. Análise crítica de diversos gêneros discursivos, abrangendo diferentes mídias.

Esses conteúdos são divididos nas disciplinas obrigatórias Oficina de Leitura e Produção de Textos em Língua Estrangeira I ( $3^{\circ}$ período), Oficina de Leitura e Produção de Textos em Língua Estrangeira II ( $4^{\circ}$ período), Oficina de Leitura e Produção de Textos em Língua Estrangeira III ( $5^{\circ}$ período), Oficina de Leitura e Produção de Textos em Língua Estrangeira IV ( $6^{\circ}$ período), cada uma com carga horária semestral de $60 \mathrm{~h} / \mathrm{aula}$, distribuídas em 4 aulas semanais.

O caráter instrumental dessas disciplinas foi pensado em termos de compreensão e produção escrita na língua uma vez que o perfil do egresso privilegia o trabalho com a língua escrita, conforme consta na página da Instituição na Internet e do projeto do curso (RIBEIRO ET AL., 2010, p. 20) aqui parafraseados de maneira sintetizada. Espera-se, então, do profissional formado neste curso:

reflexão analítica e crítica sobre a linguagem;

reconhecimento de demandas sociais e organizacionais relacionadas com as tecnologias (tradicionais ou novas) da edição;

- visão crítica sobre as perspectivas teóricas de estudos de linguagem e de literatura;

- uso adequado e consistente da língua portuguesa, especialmente, e línguas estrangeiras, eventualmente, na leitura e na produção de textos;

- reconhecimento de impactos diversos das tecnologias da comunicação na história de longa duração e em demandas de letramento emergentes;

- atuação segura e consistente em domínios e mercados ligados à edição;

- utilização segura e crítica de recursos que visem à melhor interação entre as pessoas, promovendo melhoria na qualidade de vida, inclusão social e digital;

- redação, edição e revisão de textos para a circulação em plataformas impressas e digitais;

- serviços de concepção, desenvolvimento e implementação de projetos editoriais, de maneira ajustada ao público-alvo; 
- domínio de processos de edição de textos que acompanham edições sonoras, audiovisuais e de multimídia, publicações digitais, tratamento de textos didáticos e paradidáticos, textos de compilação, de crítica e de criação;

- domínio da língua nacional e das estruturas de linguagem aplicáveis a obras literárias, científicas, instrumentais, culturais e de divulgação; competências de linguagem visual, incluindo o conhecimento de produção de imagens;

competências relacionadas ao uso das linguagens em multimídia;

- . planejamento, organização, sistematização e gestão dos processos editoriais;

- conhecimentos sobre a história do livro, da arte e da cultura;

- avaliações críticas das produções editoriais e do mercado cultural;

- promoção da democratização da leitura e do acesso às informações e aos bens culturais;

O instrumento apresentado a seguir foi delineado e usado na disciplina Oficina de Leitura e Produção de Textos em Língua Estrangeira IV ( $6^{\circ}$ período), no segundo semestre de 2014 e no primeiro semestre de 2017, quando o autor lecionou a disciplina. Foram aplicados questionários aos alunos presentes no primeiro dia de aula, os quais em momento algum se mostraram resistentes. Esses questionários, após recolhidos, foram lidos, seus resultados comentados com os alunos, e estes esclareceram alguns pontos ao professor, referindo-se na maioria das vezes às suas experiências anteriores. O foco deste artigo é na proposta do instrumento, enfatizando seus potenciais, e não nas respostas dos alunos.

\section{O instrumento}

O instrumento de coleta de informações foi desenvolvido com o intuito de se obter informações sobre: experiências prévias dos alunos com relação ao estudo e à aprendizagem de inglês; suas compreensões do contexto social do curso e da profissão, incluindo aqui o que eles (alunos) pensam mais necessitar em termos de conhecimentos do idioma, o que eles gostariam de saber fazer em inglês, e do que sentem falta no conhecimento desse idioma; ainda, o que consideram ser suas necessidades em termos de conhecimentos linguísticos, organização textual, de estratégias de leitura e de aprendizagem e sobre produção escrita. Este instrumento foi baseado nas ideias já 
apresentadas neste artigo, numa perspectiva em que o ensino seja centrado no aluno e em suas reais necessidades.

O questionário divide-se em três partes: a primeira, Experiência prévia, a segunda, Entendimento de contexto social, e a terceira, Necessidades de Aprendizagem (uma página com quadros para marcação). Nas duas primeiras partes os alunos são convidados a escrever de maneira a melhor expressarem suas experiências, anseios, ressentimentos, necessidades e conhecimentos do contexto social. Este é o momento de o aluno colocar sua voz por meio da escrita. Observa-se que as questões não exigem respostas objetivas, mas relatos, descrições ou opiniões. Na terceira parte, há liberdade para o aluno marcar mais de um tópico dos previstos em itens maiores, assim denominados: Conhecimento de Estratégias de Leitura, Conhecimentos Linguísticos, Conhecimentos sobre Organização interna do texto, Sobre a escrita em língua inglesa. $O$ fato de essa parte ser fechada não tira o caráter de se dar voz ao aluno. A colocação dos itens no instrumento é para que os alunos possam visualizar o que já deve ter sido trabalhado ou pode ainda ser trabalhado com ele e que possivelmente ele ainda tenha dúvida ou dificuldades. Ou a marcação de um item pode ser também por ele não ter sido trabalhado anteriormente, merecendo destaque no curso.

Sobre a primeira parte, Experiência Prévia, ao se solicitar do aluno um relato sobre suas experiências no estudo da língua, considera-se as mais diversas pelas quais o aluno certamente já passou ou pode ter passado: escola regular, curso livre, curso de Letras em si. É solicitado também que ele se posicione para que se entenda como o aluno se vê naquele momento, seja frustrado, motivado, com sensação de que há algo ainda a aprender. Também, o aluno pode se expressar sobre o que o levou, em suas experiências, a ter a atitude que ele tem hoje pela língua ou por aprender aquela língua, ou seja, se ele gosta, não gosta, por que, o que o motiva ou o desmotiva. Ao se fazer tal solicitação ao aluno, julga-se importante ter em mente que ele não é uma tábula rasa, mas um ser que chega naquele contexto de ensino com sensações, sentimentos e experiências que podem ter ajudado a construir a sua condição de estudante. Essa parte é mostrada no quadro 2. 
Quadro 2: Primeira parte do instrumento: Experiência Prévia.

\section{Análise de Necessidades / Needs Analysis}

Experiência prévia/ previous experience: Escreva um relato sobre sua experiência prévia em estudos envolvendo língua inglesa. Você pode levar em conta suas experiências na escola regular, em cursos livres, no curso de Letras. Não deixe de se posicionar sobre esses acontecimentos.

$\mathrm{Na}$ segunda parte, Entendimento de Contexto Profissional, o foco é na conscientização para o estudo de línguas estrangeiras no curso em questão. Optou-se, por questões de espaço na confecção do instrumento e de tempo na aplicação, em usar o texto publicado na página da Instituição sobre o perfil do aluno egresso. Levou-se em consideração que, provavelmente, os alunos leram esse texto quando intentaram ingressar no curso, mas isso nem sempre acontece. Muitas vezes também, como pode acontecer em cursos voltados a outras áreas em que o inglês se insere, há uma crença de que não se precisava daquela disciplina no currículo, pois não está voltada para a formação profissional específica.

No caso do Curso de Letras Bacharelado com ênfase em edição, é claro no texto que o uso da língua estrangeira em contexto escrito pode acontecer na vida do profissional formado. A sugestão que se faz em termos de adaptação é que este momento de análise de necessidades é também um momento para o aluno ter consciência maior sobre o curso em que ele se insere, seu papel na sociedade após graduado e em que ponto as aulas de língua estrangeira com caráter instrumental são necessárias e importantes no curso. Por isso, a partir da leitura do perfil do egresso, pede-se ao respondente que elenque conhecimentos em língua estrangeira possíveis de serem utilizados na vida profissional.

Nas turmas em que o instrumento foi utilizado, percebe-se que alguns alunos já se inserem de alguma maneira no mercado editorial, como estagiários ou como funcionários contratados, e reconhecem que o inglês, no caso, é ou pode ser necessário. Eles relatam que podem lidar com mensagens de correio eletrônico do exterior, textos traduzidos para revisão, consultar textos na língua, utilizar softwares com instruções em inglês. Os alunos também podem se tornar conscientes sobre isso se ainda não estão atuando no mercado. 
Ainda se pergunta, nesta segunda parte, sobre o que os alunos pensam que precisam, gostariam de saber e sentem falta no conhecimento de língua. Essa pergunta é coerente com a primeira parte ao se considerar que o aluno tem conhecimento prévio na língua estudada e vivenciou experiências anteriores, até mesmo porque este não é o único semestre no curso em questão em que ele estuda inglês, mas é o final da sequência de disciplina conforme já mostrado. Mas, na elaboração desses itens, considerou-se também o fato de o aluno ter conhecimento prévio de inglês além do trabalho desenvolvido com e por ele na graduação em Letras. Este é o raciocínio que se sugere para a adaptação desse instrumento em outros contextos.

Acrescenta-se que nenhuma aprendizagem é completa, que há sempre algo de que se sente falta, de que se precisa ou que se gostaria de saber. Note-se, pois, que isso está de acordo com a proposição teórica de ESP apresentada e que fundamentou a elaboração do instrumento.

Algumas respostas podem surgir com relação ao uso de outras habilidades e conhecimentos em língua estrangeira não previstos na concepção das disciplinas, como por exemplo, no caso, aprender pronúncia, fluência oral. Com isso, o professor pode promover uma discussão sobre ESP em si, mostrando que há outros anseios e desejos além do que se propõe para estudo pelo aluno num período de tempo restrito, conscientizando-o mais sobre a situação de ensino e aprendizagem e de outras oportunidades.

A segunda parte do instrumento é apresentada no quadro 3. 


\section{The ESPecialist: Descrição, Ensino e Aprendizagem, Vol. 39 No. 1 jan-jul 2018 \\ https://revistas.pucsp.br/esp CThe ESPecialist}

ISSN 2318-7115

Quadro 3: Segunda parte do instrumento: Entendimento do contexto social

Entendimento do contexto social / understanding the social context: $O$ texto a seguir é a descrição do perfil do egresso do seu curso descrita na página da Institucional na Internet. Leia antes de responder às próximas perguntas.

Letras (Tecnologias de edição)

O Bacharelado em Letras, com linha de formação em Tecnologias de edição, tem por objetivo formar profissionais preparados para o tratamento editorial de textos originais e sua publicação, tendo em vista as diversas tecnologias de escrita/leitura, de natureza impressa e digital. Esses profissionais estão ligados ao campo da edição e podem atuar como editores de texto, assistentes editoriais, revisores, além de poderem atuar na concepção e no reposicionamento de projetos.

O Curso de Bacharelado em Letras pretende preparar o profissional para a identificação, a formulação e a resolução de problemas em seu âmbito de trabalho, com criatividade, sempre visando à qualidade, à sustentabilidade e à mediação cultural. Os conhecimentos sólidos em língua portuguesa e literatura são associados aos conhecimentos do eixo de edição, ao longo do qual são enfocados processos e produtos editoriais.

\section{São ações características desse profissional:}

- refletir analítica e criticamente sobre a linguagem como fenômeno psicológico, social, histórico, cultural, político e ideológico;

- reconhecer demandas sociais e organizacionais em que possa atuar na facilitação e na reflexão sobre a comunicação, especialmente em suas relações com as tecnologias da edição, sejam elas tradicionais ou novas;

- ter visão crítica sobre as perspectivas teóricas estudadas;

- perceber formas de atuação em diferentes contextos inter e socioculturais;

- usar a língua portuguesa, especialmente, e línguas estrangeiras, eventualmente, de forma adequada e concisa, tanto na leitura quanto na produção de textos (incluindo edição e revisão);

- reconhecer aspectos históricos, sociais e políticos impactados pelas tecnologias da comunicação, tanto na história de longa duração quanto em demandas de letramento imediatos;

- atuar com segurança e consistência em domínios e mercados ligados à edição;

- utilizar, com segurança e senso crítico, recursos informáticos e outros que venham a existir em prol da melhor interação entre as pessoas, de forma a ter sua atenção centrada no leitor/usuário e nas possibilidades de inclusão social e digital;

- redigir, editar e revisar textos para a circulação em plataformas impressas e digitais;

- prestar serviços de concepção, desenvolvimento e implementação de projetos editoriais, visando

sempre à comunicação mais ajustada aos públicos aos quais o produto editorial se destina;

- dominar processos de edição de texto tais como: resumos, apresentações, textos de capa de livros,

textos de revistas, textos que acompanham edições sonoras, audiovisuais e de multimídia, textos para

publicações digitais, tratamento de textos didáticos e paradidáticos, textos de compilação, de crítica e de criação;

- dominar a língua nacional e as estruturas de linguagem aplicáveis a obras literárias, científicas,

instrumentais, culturais e de divulgação em suas diferentes formas: leitura, redação, interpretação, avaliação e crítica;

- atentar para os diferentes níveis de proficiência dos públicos a que se destinam as produções editoriais;

- ter competência em linguagem visual, como o conhecimento de produção de imagens;

- ter competências em linguagem de multimídia, como o conhecimento de processos de produção e edição de páginas e outras publicações em Internet;

- desenvolver ações de planejamento, organização, sistematização e gestão dos processos editoriais;

- ter conhecimento sobre a história do livro, da arte e da cultura;

-fazer avaliações críticas de produções editoriais e do mercado da cultura;

- agir no sentido de democratizar a leitura e o acesso às informações e aos bens culturais;

- assimilar criticamente conceitos que permitam a compreensão das práticas e teorias referentes aos processos de edição. 
Das atividades descritas no texto sobre o profissional de Letras com ênfase em Tecnologias da Edição, em quais delas você espera que pode fazer uso de conhecimentos em Língua Inglesa? Como? E que tipos de conhecimentos você espera que serão requisitados de você como profissional?

Para atuar como um profissional de acordo com a descrição que você leu, o que você:

a) Necessita em termos de conhecimentos de Língua Inglesa?

b) Gostaria de saber em Língua Inglesa?

c) Sente falta no seu conhecimento de Inglês?

A terceira e última parte do instrumento, Necessidades de Aprendizagem, referese àquilo que o aluno considera que ele realmente precisa aprender, e por isso os tópicos apresentados para serem assinalados são apresentados de maneira sistemática e explicada, de modo que sua marcação promova e demonstre consciência pelo aluno. Os itens referem-se, neste caso, aos tópicos possivelmente trabalhados nas disciplinas anteriores em temos de conhecimento de estratégias, conhecimentos linguísticos, conhecimentos sobre organização textual e produção escrita. Não necessariamente todos os itens teriam sido trabalhados nas disciplinas anteriores e o foco principal da disciplina Oficina de Leitura e Produção de Textos em Língua Estrangeira IV - Inglês é o aprofundamento da leitura em língua estrangeira e maior desenvolvimento da escrita visando o meio acadêmico.

Nas duas situações em que este instrumento foi utilizado, a marcação maior acontece nos conhecimentos linguísticos e na produção escrita. Isso demonstra que esses tópicos relacionados precisam ainda ser revisados e enfatizados na disciplina.

Quanto à possibilidade de adaptações para cursos iniciantes de ESP, pode ser pertinente referir-se ao conhecimento linguístico do inglês com exemplos para que os alunos consigam visualizar o que se diz por grupo nominal, por exemplo, ou marcadores do discurso. Também, sobre as estratégias, não necessariamente precisam ser nomeadas, mas sim explicadas. Outra opção para se promover no aluno a percepção de suas necessidades com relação a esses tópicos é perguntar se ele põe em pratica ou não esses conhecimentos na leitura e na escrita em português.

A terceira parte do instrumento é apresentada no quadro 4. Esta apresentação encerra essa seção em que, além da descrição do instrumento, consideraram-se possíveis ajustes a outras situações de ensino e de aprendizagem de línguas para fins específicos de 
leitura e escrita. Ainda, acredita-se que há possibilidades de adaptação para outras situações de ensino e de aprendizagem de inglês instrumental, ou de outra língua, em que outras habilidades sejam enfocadas. Passa-se, portanto, às considerações finais após a visualização do quadro 4 .

Quadro 4: Terceira parte do instrumento: Necessidades de aprendizagem.

Necessidades de Aprendizagem / Learning needs: Em cada grupo, circule os tópicos sobre os quais você acha que tem mais dificuldade na leitura em inglês:

Conhecimento de Estratégias de Leitura:

- Entendimento de Informação verbal e não verbal.

- Skimming: leitura rápida para entender sobre o que trata o texto.

- Scanning : leitura mais detalhada para checar informações específicas no texto

- Ativação de Conhecimento prévio na leitura: previsão, conhecimento de vocabulário sobre o assunto, conhecimento sobre o assunto em si, conhecimento sobre o gênero discursivo em questão.

- Inferência lexical: reconhecimento de palavras transparentes e cognatas, inferência de significado pelo contexto.

- Uso de dicionário

Conhecimentos Linguísticos:

- Grupos nominais (núcleo, determinantes, modificadores)

- Grupos verbais (tempos verbais, verbos auxiliares e principais, verbos modais)

- Partes da sentença: (Sujeito, verbo, objeto, complemento)

- Referência pronominal. (pronomes pessoais, pronomes demonstrativos, pronomes relativos)

- Grau de adjetivo (comparativos de superioridade, inferioridade e igualdade, superlativos)

- Marcadores Discursivos: (relações de causa, consequência, condição, adição, síntese, finalidade, modo, tempo, contraste, exemplificação)

- Formação de palavras: (prefixos, sufixos, palavras derivadas e palavras compostas)

Conhecimentos sobre Organização interna do texto:

- Coerência: identificação da ideia central de cada parágrafo e do tópico frasal; percepção da escolha vocabular e rastreio de palavras-chave; reconhecimento da sequencia de ideias nos parágrafos e no texto;

- Coesão: relações de coordenação, subordinação e expressões de transição entre frases e parágrafos.

Sobre a escrita em língua inglesa:

- Escrita de tópico frasal;

- Estruturação e Escrita de parágrafo;

- Elaboração de resumos, esquemas, mapas mentais ou listas a partir de outros textos lidos;

- Elaboração de gráficos e tabelas a partir de informações no texto em inglês;

- Escrita em inglês de textos de correspondência: e-mail, carta, bilhete

- Escrita em inglês de textos de divulgação: notícias, resenhas, anúncios, cartazes, panfletos, folders

- Consideração do processo de escrita: planejamento (o que, para quem, para que, por que escrever), momento da escrita e escolhas linguístico-discursivas, revisão do texto escrito e publicação. 


\section{Considerações Finais}

Neste artigo apresentou-se uma proposta de instrumento para análise de necessidades em um curso de ESP voltado para leitura e produção textual em inglês num curso de Bacharelado em Letras com ênfase em edição. A base teórica norteadora da confecção do instrumento foi a mesma que guia o ensino de línguas para fins específicos nos mais diferentes contextos, levando-se em conta necessidades de uso da língua na situação alvo, o que já se sabe e o que é preciso aprender, os anseios e desejos de quem deve ou quer aprender inglês. $\mathrm{O}$ instrumento foi descrito e explicado, e apresentaram-se possíveis adaptações a serem pensadas por professores que queiram utilizá-lo. Entendese que esse instrumento pode ser revisto e usado em situações semelhantes ou diferentes, considerando-se as informações específicas sobre perfil do egresso e seus conhecimentos.

A diferença entre o instrumento apresentado e outras análises de necessidades referenciadas neste artigo reside na valorização da voz do aluno para que ele se expresse sobre suas experiências, seu conhecimento sobre a língua, sobre as estratégias, sobre discurso, suas habilidades, suas frustrações e desejos, reforçando, assim, o caráter de centralização do ensinar e do aprender na figura discente no que se refere à organização do conteúdo e da metodologia a ser adotada. Tentou-se mostrar, aqui, também, que conhecer o aluno em termos de seus ressentimentos, anseios, suas experiências prévias estudando o idioma vai além do objetivo de delineamento do curso, mas contribui para melhor se estabelecerem as relações entre docente e discente, tornando ambos mais conscientes de seus papeis no ensinar e no aprender. Assim, essas pessoas podem tornar esses processos mais humanos e libertadores, pois que conhecendo a si e o outro, e estando mais consciente da situação social e educacional em que se inserem, o professor e o aluno podem, pelo diálogo, criar e recriar o ensinar e o aprender, tentando livrar-se da dominação e da opressão (FREIRE, 2000). Isso também se relaciona com o importar-se com a qualidade de vida em sala de aula (MILLER; GIEVE, 2006), ou seja, professores podendo entender melhor seus alunos como agentes na sala de aula, e estes se entendendo sem perder de vista a situação em que se inserem, de modo a poderem ser aprendizes autônomos da língua estrangeira em outras situações, não reclamando de situações das quais não reconhecem sucessos. 
Nesse sentido, o instrumento pode ser um elemento que ajude na conscientização dos alunos sobre o papel da língua estudada nestes moldes (ESP) para sua atuação como graduado na área em questão, sobre o papel do inglês na sociedade no que tange a área específica e o perfil do egresso.

Por fim, ao reconhecer a importância de se conhecerem mais experiências e pesquisas relativas à análise de necessidades e a discussão sobre a relação entre docentes e discentes, este artigo tem a mesma visão da conclusão apresentada por Ramos, LimaLopes e Gazotti-Vallim (2003): a análise de necessidades não é definitiva e pode ser sim contínua, aprimorando cada vez mais as compreensões das situações de ensino e de aprendizagem de inglês. Ainda, julga-se, aqui, imperativo que não se esqueça, neste trajeto de busca por novas possibilidades, que os próprios alunos participem das discussões em torno de seu próprio aprender.

\section{Referências Bibliográficas}

ALMEIDA, Amanda Maria B. de Souza; SILVA, Thalita Barbosa. Análise de necessidades de inglês para alunos do curso de Análise e Desenvolvimento de Sistemas. CONICT - IFSP: $7^{\circ}$ Congresso de Iniciação Científica e Tecnológica do IFSP - MatãoSP, 2016. Disponível em http://mto.ifsp.edu.br/images/CPI/Anais/IC/1668.pdf. Acesso em 05/04/2017.

DUDLEY-EVANS, Tonny.; ST. JOHN, Maggie Jo. Development in English for Specific Purposes: A Multidisciplinary Approach, Cambridge: Cambridge University Press, 2009.

FREIRE, Paulo. A Pedagogia do Oprimido. 28 ed. São Paulo: Paz e Terra Editores, 2000. HUTCHINSON, Tom; WATERS, Alan. English for Specific Purposes: a learning-centre approach. Cambridge: CUP, 1987.

JORDAN, R. R. English for Academic Purposes- a guide and resource book for teachers. Cambridge: Cambridge University Press, 1998.

LANKSHEAR, Colin; KNOBEL, Michele. Pesquisa Pedagógica - do projeto à implementação. Porto Alegre: Artmed, 2008.

LONG, Michael. Overview: A rationale for needs analysis and need analysis research. In: LONG, Michael Second Language Needs Analysis. Cambridge: Cambridge University Press, 2005, p. 1-16.

SAES, Maria Elizete Luz. Exames de Proficiência em Língua Inglesa: análise de necessidades e propostas metodológicas. The ESPecialist, v. 34, n 1, 2013, p.91-112. 
MILLER, Inés K.; GIEVE, Simon. What do we mean by 'Quality of Classroom Life'. In.: GIEVE, S. and MILLER, I. K. (Ed.) Understanding the language classroom, Hampshire, U K: Palgrave Macmillan. 2006, p. 18-47.

RAMOS, Rosinda Castro Guerra; LIMA-LOPES, Rodrigo; GAZOTTI-VALLIM, Maria Aparecida. Análise de Necessidades: Identificando Gêneros Acadêmicos em um Curso de Leitura Instrumental. The ESPecialist, vol. 25, no 1 São Paulo: PUC-SP, 2004, p 1-29.

RIBEIRO, Ana Elisa; VILLELA, Ana Maria Nápoles Villela; COELHO, Olga Valeska Soares; AVELAR, Silvana Lúcia Teixeira. Projeto Político-Pedagógico para Implantação do Curso de Graduação em Letras (Linha de Formação em Tecnologias da Edição). Belo Horizonte: CEFET-MG, 2010.

SARMENTO, Maria Edileuda do Rego. Análise de necessidades de inglês para fins específicos em um curso de graduação em turismo. Dissertação de Mestrado em Estudos da Linguagem. Natal: UFRN, 2012, 124f.

SILVA, Jessica Cristina da; BONIFÁCIO, Carla Alecsandra de Melo. Inglês para hotelaria: análise das necessidades de aprendizado dos profissionais em hotéis de grande porte de João Pessoa/PB. Revista Hospitalidade. São Paulo, v. XII, n. 1, jun. 2015, p. 438- 462 .

Disponível em https://www.revhosp.org/hospitalidade/article/download/562/659.

Acesso em 05/04/2017

SOUZA, Sheilla Andrade. Análise de necessidades e o ensino de línguas para fins específicos. Revista Desempenho. Brasília: Programa de Pós-Graduação em Linguística Aplicada UnB, número 22, 2014, p. 1-16.

VILAÇA, Márcio Luiz Corrêa. English for Specific Purposes: fundamentos do ensino de inglês para fins específicos. Revista Eletrônica do Instituto de Humanidades. Rio de Janeiro, UNIGRANRIO, Número XXXIV, 2010, pp. 1-12. Disponível em:

http://publicacoes.unigranrio.com.br/index.php/reihm/article/viewFile/1715/808. Acesso em $01 / 03 / 2017$.

Renato Caixeta da Silva is a full professor at the Federal Centre of Technological Education in Minas Gerais (CEFET-MG) where he has taught English since 1997. He has long experience in teaching ESP, General English, Reading Images, at Secondary Education, Undergraduation Course and Post-Graduation Courses (Master and Doctorate). He also has the following research interests: foreign language teaching and learning, teaching materials, Multimodality and Systemic-Functional Linguistics. He has been the leader of the Research Group on Teaching Materials and Resources at CEFETMG since 2012.E-mail: rencaixe@yahoo.com.br 